\title{
Sustained rheumatoid arthritis remission is uncommon in clinical practice
}

\author{
Femke HM Prince*, Vivian P Bykerk, Nancy A Shadick, Bing Lu, Jing Cui, Michelle Frits, Christine K lannaccone, \\ Michael E Weinblatt and Daniel H Solomon
}

\begin{abstract}
Introduction: Remission is an important goal of therapy in rheumatoid arthritis (RA), but data on duration of remission are lacking. Our objective was to describe the duration of remission in RA, assessed by different criteria.

Methods: We evaluated patients from the Brigham and Women's Rheumatoid Arthritis Sequential Study (BRASS) not in remission at baseline with at least 2 years of follow-up. Remission was assessed according to the Disease Activity Score 28-C-reactive protein (DAS28-CRP4), Simplified Disease Activity Index (SDAl), and Clinical Disease Activity Index (CDAl) scores, and the recently proposed American College of Rheumatology (ACR)/European League against Rheumatism (EULAR) criteria for remission. Analyses were performed by using Kaplan-Meier survival curves.

Results: We identified 871 subjects with $\geq 2$ years of follow-up. Of these subjects, 394 were in remission at one or more time-points and not in remission at baseline, according to at least one of the following criteria: DAS28-CRP < $2.6(n=309)$, DAS28-CRP $<2.3(n=275)$, SDAI $(n=168)$, CDAI $(n=170)$, and 2010 ACR/EULAR $(n=158)$. The median age for the 394 subjects at entrance to BRASS was 56 years; median disease duration was 8 years; $81 \%$ were female patients; and $72 \%$ were seropositive. Survival analysis performed separately for each remission criterion demonstrated that $<50 \%$ of subjects remained in remission 1 year later. Median remission survival time was 1 year. Kaplan-Meier curves of the various remission criteria did not significantly differ ( $P=0.29$ according to the logrank test).
\end{abstract}

Conclusions: This study shows that in clinical practice, a minority of RA patients are in sustained remission.

\section{Introduction}

Rheumatoid Arthritis (RA) is characterized by joint inflammation leading to joint destruction. This causes decreased functional capacity, work disability, and reduced quality of life [1]. Advances in the understanding of RA pathogenesis have led to the development of novel therapeutic targets and new treatment guidelines aiming for remission [2]. However, it is not generally accepted how best to define disease remission [3]. At least three remission definitions are in use: the Disease Activity Score (DAS) $-28<2.6$ and $<2.3$ score, Simplified Disease Activity Index $(\mathrm{SDAI}) \leq 3.3$ score and Clinical Disease Activity Index (CDAI) $\leq 2.8$ score [4-7]. Recently, the American College of Rheumatology (ACR), the European League against Rheumatism (EULAR), and the Outcome

\footnotetext{
* Correspondence: femkeprince@gmail.com

Division of Rheumatology, Immunology and Allergy, Brigham and Women's Hospital, Harvard Medical School, Boston, MA, USA
}

Measures in Rheumatology Initiative (OMERACT) developed new remission criteria [8,9], the ACR/EULAR provisional definition of remission. All of these remission definitions examine disease activity at a single point in time, making them less useful for long-term follow-up studies $[10,11]$. Studies evaluating tight control and treatto-target strategies advocate that remission should be reached as soon as possible and should be maintained during the course of the disease $[12,13]$. The investigators suggest that remission must be sustained to halt joint damage [12,13]. Relatively little is known about the duration of remission in clinical practice. With remission being a stated goal of RA treatment, it would thus be important to compare remission criteria and to examine the duration of RA remission [2].

To understand remission duration in RA, we examined a large clinical cohort of patients followed up for multiple years. Our aims were (a) to describe the duration of remission, regardless of how these patients

C Biomed Central

(c) 2012 Prince et al.; licensee BioMed Central Ltd. This is an open access article distributed under the terms of the Creative Commons Attribution License (http://creativecommons.org/licenses/by/2.0), which permits unrestricted use, distribution, and reproduction in any medium, provided the original work is properly cited. 
achieved remission; and (b) to compare remission duration according to different remission criteria.

\section{Materials and methods}

The Brigham Rheumatoid Arthritis Sequential Study (BRASS) cohort

BRASS is a prospective, observational, single-center cohort with RA patients diagnosed by board-certified rheumatologists at the Brigham and Women's Hospital Arthritis Center [14]. Patients are prospectively monitored, and their RA is managed according to the preference of the treating rheumatologist. Patients complete a series of questionnaires every 6 months, and their rheumatologists carry out an annual structured physical examination with history, laboratory tests to determine RA activity, functional status, and adverse events. The study was approved by the Institutional Review Board for Brigham and Women's Hospital, and all patients gave written informed consent.
For the Kaplan-Meier analyses, we included only the 394 subjects with (a) at least 2 years follow-up, (b) at least one remission time-point with subsequently 12 months or more follow-up; and (c) were not in remission at entrance of BRASS (see Figure 1). The first remission time point for each patient was considered baseline $(T=0)$. Visits included ranged from March 2003 until June 2010.

\section{Remission criteria}

The annually collected disease-activity variables were analyzed, and the proportion of patients in a state of remission was determined by the following criteria: DAS28-CRP4 $<2.6$ and $<2.3$, SDAI $\leq 3.3$, CDAI $\leq 2.8$, and the ACR/EULAR remission criteria. The remission criteria are described in detail in Table 1. The DAS28CRP4 is based on a 28-joint tender and swollen count, patient's global assessment of disease activity, and the

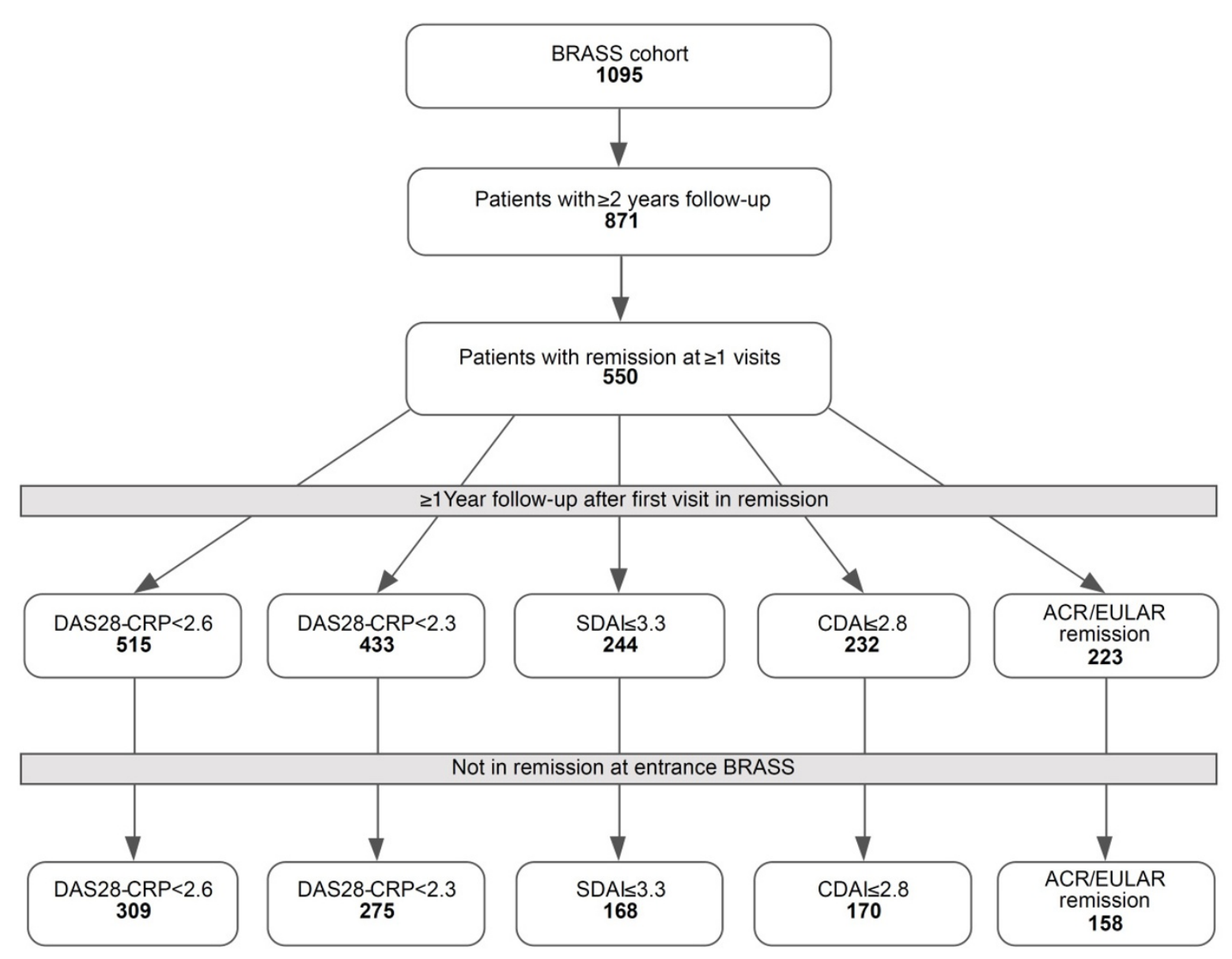

Figure 1 Subject selection, illustrating the study cohort assembly. For the Kaplan-Meier analyses, we include only subjects with at least 2 years of follow-up, at least one remission time-point with subsequently 12 months or more of follow-up, and who were not in remission at entrance into BRASS. BRASS, Brigham Rheumatoid Arthritis Sequential Study; DAS28-CRP, Disease Activity Score 28-C-reactive protein; ACR, American College of Rheumatology; SDAl, Simplified Disease Activity Index; CDAl, Clinical Disease Activity; EULAR, European League Against Rheumatism. 
Table 1 Various definitions of remission in RA used in this study

\begin{tabular}{|c|c|c|}
\hline \multicolumn{2}{|c|}{ Definition remission } & \multirow{2}{*}{$\begin{array}{l}\text { Threshold of sum variables } \\
<2.6\end{array}$} \\
\hline DAS28-CRP4 & $0.56^{*} \sqrt{(T J C 28)}+0.28^{*} \sqrt{ }(\mathrm{SJC} 28)+0.36^{*} \ln (\mathrm{CRP}+1)+0.014^{*} \mathrm{GH}+0.96$ & \\
\hline SDAl & TJC28 + SJC28 + CRP + PTglobal + MDglobal & $\leq 3.3$ \\
\hline CDAl & TJC28 + SJC28 + PTglobal + MDglobal & $\leq 2.8$ \\
\hline ACR/EULAR & TJC28* $\leq 1 \&$ SJC28* $\leq 1 \&$ CRP $\leq 1 \&$ PTglobal $\leq 1$ & $\leq 4$ \\
\hline
\end{tabular}

TJC28, 28 tender-joint count; SJC28, 28 swollen-joint count; CRP, C-reactive protein (mg/L DAS28-CRP4 and mg/dl other definitions); GH, General Health on a 0to $100-\mathrm{mm}$ Visual Analogue Scale (VAS); PTglobal, patient's global assessment on a 0- to 10-cm VAS;

MDglobal, physician's global assessment on a 0 - to 10-cm VAS. *The ACR/EULAR definition prefers the inclusion of feet and ankles for the evaluation of remission, but use of the 28-joint count is allowed because the overall impact due to reduced joint count was found to be small.

CRP [6]. Originally, remission threshold value for DAS28-CRP was set at 2.6, equal to the DAS28-ESR. However, because research has suggested that the cutoff values to classify remission are lower in DAS28-CRP compared with the DAS28-ESR, we also evaluated 2.3 as threshold value $[15,16]$. The SDAI and CDAI scores use the same variables as the DAS28-CRP (tender and swollen 28-joint count, patient's global assessment and CRP in the case of SDAI), but also include the physician's global assessment of disease activity [4,7]. The new ACR/EULAR remission criteria require that tender and swollen joint count, CRP (milligrams per liter), and patient's global assessment (on a 0 to 10 visual analogue scale) all individually to be $\leq 1[8]$.

\section{Statistical analyses}

Descriptive statistics were reported as medians (interquartile range, IQR) for continuous variables and as frequencies (percentage) for categoric variables. The Mann-Whitney $U$ test was used to compare continuous variables, and the Fisher Exact test for categoric variables. Patient and disease characteristics of the 224 patients with $<2$ years of follow-up and not included in the study were compared with the 871 patients included in the study ( $\geq 2$ years of follow-up).

The primary outcome was time in sustained remission according to the DAS28-CRP4, SDAI, CDAI, and ACR/ EULAR criteria. The Kaplan-Meier curves and log-rank test were used to assess the difference of survival functions based on the five remission definitions. We separately calculated the number of subjects regaining remission for the DAS28-CRP $<2.6$. Based on prior literature, we hypothesized that durability of remission may be different for subjects according to gender, serologic status (seropositive $=$ rheumatoid factor $(\mathrm{RF})$ or anti-cyclic citrullinated peptide (CCP) positive), and/or disease duration at start of remission [17-20]. Therefore, we evaluated subjects in sustained DAS28-CRP $<2.6$ remission stratified according to these subgroups. We decided on a cut-off of 5 years for disease duration, because 0 to 5 years was the lowest quartile of disease duration of all patients at their first visit in remission (median, 11 years; IQR, 5 to 22).
For every RA patient in BRASS, the first time-point in remission according to one of the remission criteria was considered the baseline $(\mathrm{T}=0)$ for that specific definition of remission. To calculate time in remission according to that definition, disease activity at consecutive annual time points was evaluated according to the remission criteria of that definition. After the subject no longer met the definition of a given remission criterion or was censored because of missing data, the data on the patient thereafter were ignored.

Apart from the survival analyses that censored patients who did not meeting the definition of remission, we also calculated the percentage of follow-up time spent in remission, allowing subjects to regain remission. For this secondary analysis, in contrary to the Kaplan-Meier analyses, we included all 871 subjects, regardless of whether they began BRASS follow-up in remission.

Nine percent of data on remission-criteria variables was missing. Multiple imputation by chained equations was performed to replace missing values in the variables requested for calculation of remission criteria [21]. Multiple imputation was applied only if a part of the remission variables were available; if all data were missing, the patient was considered lost to follow-up from that time on.

Outcomes were calculated by using statistical software SPSS 15.0.1. (SPSS Inc., Chicago, IL, USA) and SAS 9.2. (SAS Institute Inc., Cary, NC, USA).

\section{Results}

Patient and disease characteristics

Of the 1,095 RA patients in BRASS, 871 had at least 2 years of follow-up. Of the 871 subjects with at least 2 years of follow-up, 550 were in remission at one or more time-points. Of these subjects, 394 had 12 months of follow-up after their first remission time point and were not in remission at entrance into BRASS (see Figure 1). Median follow-up time for the cohort was 5.4 years (IQR, 4.5 to 6.5 ). Patient and disease characteristics at entrance into the BRASS cohort are given in Table 2. Patient and disease characteristics at entrance into BRASS of excluded subjects $(<2$ years of follow- 
Table 2 Patient and disease characteristics at entrance into BRASS cohort for subjects with $\geq 2$ years of followup, in remission at one or more visit to any remission definition, and not in remission at entrance

\begin{tabular}{ll}
\hline $\boldsymbol{N}=\mathbf{3 9 4}$ & $\boldsymbol{n}(\%) /$ Median (IQR) \\
\hline Female & $320(81)$ \\
Age (years) & $56(45-63)$ \\
Positive anti-CCP or RF status & $282(72)$ \\
Smoking & $24(6)$ \\
Disease duration (years) & $8(2-19)$ \\
Any stiffness & $286(73)$ \\
Stiffness duration (minutes) & $30-60(10-90)$ \\
CRP (mg/L) & $2.7(1.1-7.9)$ \\
NSAIDs & $244(62)$ \\
Corticosteroids & $103(26)$ \\
MTX & $196(50)$ \\
Nonbiologic DMARDs & $137(35)$ \\
(not MTX) & \\
Biologics & $133(34)$ \\
\hline
\end{tabular}

$C C P$, cyclic citrullinated peptide; $C R P, C$-reactive protein; DMARD, diseasemodifying antirheumatic drug; MTX, methotrexate; RF, rheumatoid factor.

up) did not differ significantly from included subjects on median age, anti-CCP, and/or RF positivity, median CRP, morning stiffness, or use of medications. However, they did differ on gender (77\% female; $P=0.049)$, smoking status (13\% smokers; $P=0.029)$, median disease duration (7 years $P=0.024)$; use of MTX (35\%; $P=$ $0.001)$, and biologic DMARDs $(28 \% ; P=0.006)$.

\section{Durability of sustained remission according to various remission definitions}

The proportion of subjects remaining in remission according to the different remission criteria is shown in Figure 2. After 1 year, more than half of the RA patients previously in remission had fallen out of remission. Median remission survival, irrespective of the remission definition, was 1 year. The proportion of subjects considered to be in remission did not differ according to different remission criteria (log-rank test, $P=0.29$ ). Remission using the DAS28-CRP at a 2.6 cut-off was met most frequently, and using SDAI and the new ACR/EULAR definition, least frequently.

One-hundred-eighty-two subjects had a median DAS28-CRP score of 3.8 (median tender-joint count of 6, swollen joint of 4, CRP of $6.6 \mathrm{mg} / \mathrm{L}$, and general health on VAS of $25 \mathrm{~mm}$ ) after they lost DAS28-CRP $<2.6$ remission after one annual visit in remission. Of these 182 subjects who were in DAS28-CRP $<2.6$ remission at one visit but not the subsequent annual visit, 41 (23\%) regained remission at the next annual visit. Thirty-six subjects had a median DAS28-CRP score of 3.7 (median tender-joint count of 5 , swollen joint of 4 , CRP of 8.3 $\mathrm{mg} / \mathrm{L}$, and general health on VAS of $18 \mathrm{~mm}$ ) after they

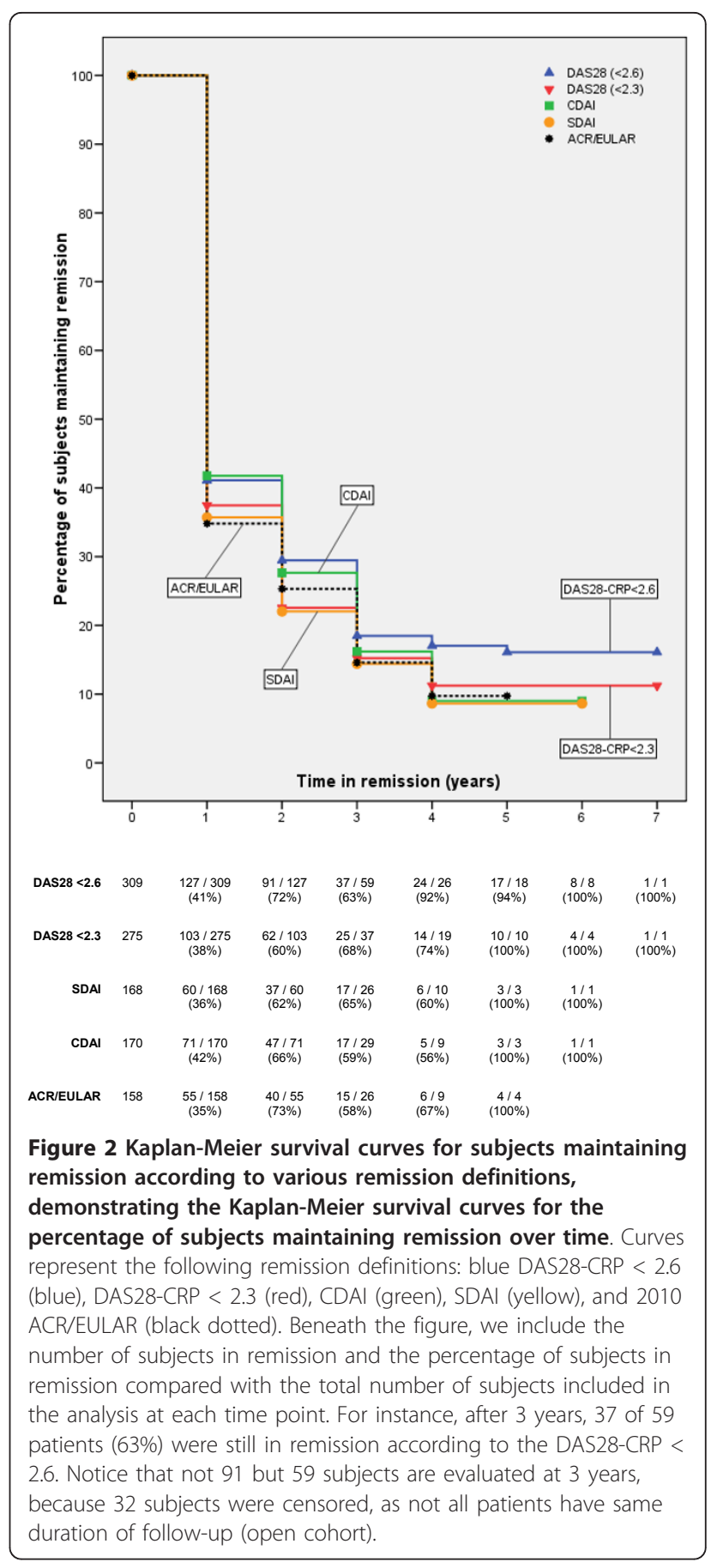

lost DAS28-CRP $<2.6$ remission after two subsequent annual visits in remission. Eleven (31\%) of these 36 subjects who were in DAS28-CRP $<2.6$ remission at two subsequent annual visits, but not the subsequent annual visit, regained remission at the next annual visit.

In Figure 3, the Kaplan-Meier curves are shown for the 309 subjects in DAS28-CRP $<2.6$ remission at $\geq 1$ visit, stratified according to gender (Figure 3a), seropositivity (Figure 3b), and disease duration (Figure 3c). 


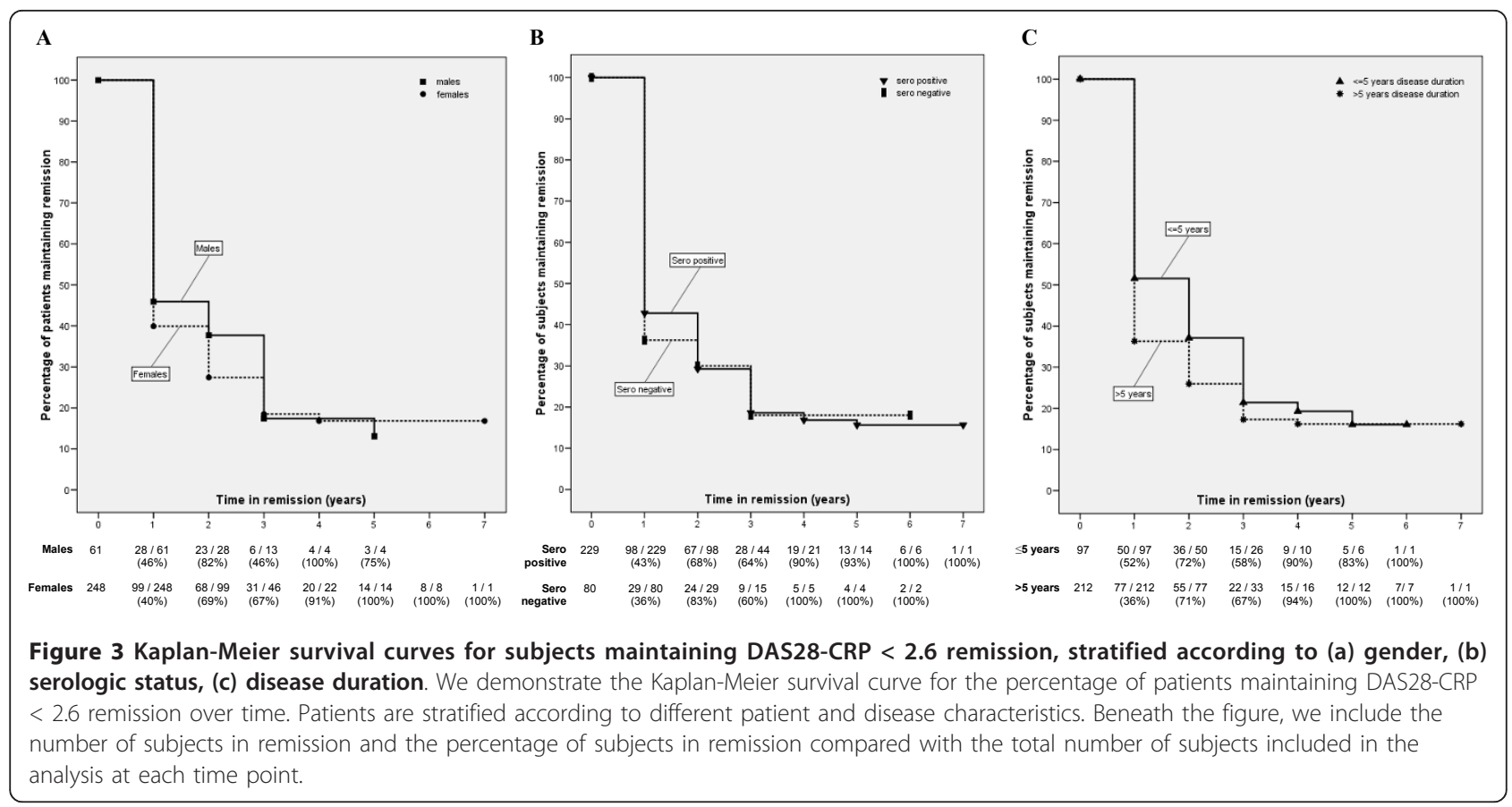

Although more males and subjects with $\leq 5$ years of disease duration maintained remission in the first years of remission, the survival curves for these subgroups were not significantly different (log-rank test, $P=0.46$ by gender, log-rank test, $P=0.12$ by disease duration). Kaplan-Meier curves for seropositive and seronegative subjects were also similar (log-rank test, $P=0.92$ )

\section{Subjects according to percentage of visits in remission in BRASS}

Considering all 871 subjects in BRASS with $\geq 2$ years of follow-up, subjects on average spent $31 \%$ of their follow-up time in DAS28-CRP $<2.6$ remission, $24 \%$ in DAS28-CRP $<2.3$ remission, $12 \%$ in SDAI remission, $15 \%$ in CDAI remission, and $10 \%$ in ACR/EULAR remission. This calculation includes patients who were never in remission and subjects in remission at entrance into BRASS.

When we selected the 394 subjects who were in remission $\geq 1$ visit and were not in remission at entrance into BRASS, the average time spent in remission was $48 \%$, according to the DAS28-CRP $<2.6,45 \%$ according to the DAS28-CRP $<2.3,44 \%$ according to the SDAI, $44 \%$ according to the CDAI, and $42 \%$ according to the ACR/EULAR. The number of subjects according to mean time in remission and the various remission criteria are summarized in Table 3.

\section{Discussion}

Because of advances made in therapy and treatment strategies, remission in RA has become the treatment goal in clinical trials and in clinical practice. However, previous studies have already suggested that remission in clinical practice might not be as common as in clinical trials $[22,23]$. The aim of our study was to evaluate whether subjects in remission maintain this state over a long period. Our analyses show that not even half of the RA patients maintained remission beyond 1 year, regardless of the remission definition (see Figure 1). Even after multiple years in remission, a patient's disease can become more active. These findings have clinical implications, in that physicians need to continue to monitor RA patients in remission closely and may need to consider treatment changes in these patients if they flare or present with sustained disease activity. According to the Kaplan-Meier survival-curve analyses, the likelihood of patients experiencing active disease after remission decreases as the years in remission increase. Whether patients were considered to be in remission depended on the criteria used, although differences in remission duration were not statistically significant. We found the SDAI and the new ACR/ EULAR criteria to be the most stringent. This is in accordance with the aims of the ACR, EULAR, and OMERACT, who requested a stringent remission definition and proposed the SDAI and newly developed ACR/EULAR remission [9]. Although the ACR/EULAR remission definition was designed and validated for use in clinical trials and not for observational studies evaluating remission in real-life clinical practice, we thought it would be interesting to evaluate the definition in the current study [8-11]. 
Table 3 Number of subjects categorized according to time spent in remission divided by subject-specific follow-up duration, for each of the remission criteria tested

\begin{tabular}{|c|c|c|c|c|c|}
\hline \multicolumn{6}{|c|}{ All subjects in BRASS with $\geq 2$ years of follow-up } \\
\hline Time in remission (\%) & $\begin{array}{l}\text { DAS28-CRP }<2.6 \\
N=871^{\mathrm{a}}\end{array}$ & $\begin{array}{l}\text { DAS28-CRP }<2.3 \\
N=871^{\mathrm{a}}\end{array}$ & $\begin{array}{l}\text { SDAI } \\
N=871^{\mathrm{a}}\end{array}$ & $\begin{array}{l}\text { CDAI } \\
N=871^{\mathrm{a}}\end{array}$ & $\begin{array}{l}\text { ACR/EULAR } \\
N=871^{\mathrm{a}}\end{array}$ \\
\hline 0 & $326(37 \%)$ & $401(46 \%)$ & $599(69 \%)$ & $610(70 \%)$ & $634(73 \%)$ \\
\hline $1-25$ & $130(15 \%)$ & $146(17 \%)$ & $94(11 \%)$ & $30(3 \%)$ & $87(10 \%)$ \\
\hline $26-50$ & $196(23 \%)$ & $163(19 \%)$ & $108(12 \%)$ & $127(15 \%)$ & $101(12 \%)$ \\
\hline $51-75$ & $121(14 \%)$ & $102(12 \%)$ & $52(6 \%)$ & $66(8 \%)$ & $39(4 \%)$ \\
\hline $76-99$ & $52(6 \%)$ & $30(3 \%)$ & $10(1 \%)$ & $17(2 \%)$ & $7(1 \%)$ \\
\hline 100 & $46(5 \%)$ & $29(3 \%)$ & $8(1 \%)$ & $21(2 \%)$ & $3(0.3 \%)$ \\
\hline Overall mean time in remission & $31 \%$ & $24 \%$ & $12 \%$ & $15 \%$ & $10 \%$ \\
\hline \multicolumn{6}{|c|}{ Selected population of subjects in BRASS } \\
\hline Time in remission (\%) & $\begin{array}{l}\text { DAS28-CRP }<2.6 \\
N=309^{\mathrm{b}}\end{array}$ & $\begin{array}{l}\text { DAS28-CRP }<2.3 \\
N=275^{\mathrm{b}}\end{array}$ & $\begin{array}{l}\text { SDAI } \\
N=168^{b}\end{array}$ & $\begin{array}{l}\text { CDAI } \\
N=170^{b}\end{array}$ & $\begin{array}{l}\text { ACR/EULAR } \\
N=158^{\mathrm{b}}\end{array}$ \\
\hline $1-25$ & $77(25 \%)$ & $89(32 \%)$ & $58(35 \%)$ & $54(32 \%)$ & $60(38 \%)$ \\
\hline $26-50$ & $133(43 \%)$ & $111(40 \%)$ & $62(37 \%)$ & $72(42 \%)$ & $64(41 \%)$ \\
\hline $51-75$ & $49(16 \%)$ & $37(13 \%)$ & $30(18 \%)$ & $24(14 \%)$ & $18(11 \%)$ \\
\hline $76-99$ & $28(9 \%)$ & $21(8 \%)$ & $6(4 \%)$ & $7(4 \%)$ & $8(5 \%)$ \\
\hline 100 & $22(7 \%)$ & $17(6 \%)$ & $12(7 \%)$ & $13(8 \%)$ & $8(5 \%)$ \\
\hline $\begin{array}{l}\text { Overall mean } \\
\text { time in remission }\end{array}$ & $48 \%$ & $45 \%$ & $44 \%$ & $44 \%$ & $42 \%$ \\
\hline
\end{tabular}

${ }^{\text {a }}$ Subjects in BRASS with $\geq 2$ years of follow-up. Maximum number of visits is eight. 'bubjects in BRASS with $\geq 2$ years of follow-up, one or more visits in remission, according to the various

definitions; $\geq 1$ year follow-up after first visit in remission and not in remission at entrance into

BRASS. Maximum number of visits is seven (because visit at entrance into BRASS is excluded).

It should be noted that aging of patients could have played a role in not fulfilling remission criteria, because subjects had a median age of 56 years at entrance to BRASS. A study from Finland evaluated individuals from the general population older than 50 years by the ACR remission criteria and concluded that the majority did not meet the criteria [24]. However, the aim of the current study was to evaluate durability of remission, not the incidence of remission. It is not likely that age could have played a major role in the fact that more than half of subjects did not meet remission criteria any more after only 1 year.

Other studies have described sustained remission in daily practice as uncommon, being reached by only $17 \%$ to $36 \%$ of RA patients for up to 6 months $[19,22,25,26]$. These studies did not evaluate time in remission beyond 6 months. A recent study investigated the probability of remaining in remission up to 24 months, according to the ACR/EULAR, SDAI, and CDAI remission criteria in two different cohorts [27]. They also concluded that long-term remission is rare, considering that the probability of a remission lasting 2 years was $6 \%$ to $14 \%$.

We evaluated differences in duration of sustained remission according to patient and disease characteristics. We did not find statistically significant differences based on gender, seropositivity, or disease duration, but these stratified analyses were underpowered and should be considered only exploratory. A trend seemed to exist toward longer remission duration in men and subjects with 5 years or less disease duration at start of remission. Schipper et al. [19] recently showed that time to achieve remission correlates with remission duration [19]. Although our data suggest the same, we cannot be sure because most BRASS patients enter the study after the initiation of disease; thus subjects could have been in remission before entrance into BRASS.

In addition to data on remission duration, we investigated patterns of regaining remission for DAS-CRP $<$ 2.6. Fewer than a quarter of subjects who were previously in remission at one visit, and then dropped out of remission, regained remission at the next annual visit. Slightly more subjects regained remission if demonstrating remission at two consecutive visits, but the percentage was still low (31\%). Subsequently, we evaluated time spent in remission during the specific follow-up period for each subject in BRASS with at least 2 years of follow-up. These data not only show that sustained remission is uncommon in clinical practice, but also that most subjects spend little follow-up time in remission. In the BRASS cohort, most subjects were in remission during less than half of their follow-up visits.

The ultimate goal of treating RA is to achieve remission and halt the progression of joint damage. Several studies show that one time point of meeting remission 
criteria does not always mean that the disease does not progress [28-30]. A longer period of meeting the remission criteria might be an indication of cessation of disease activity, rather than drug-induced disease suppression [31]. In juvenile idiopathic arthritis, patients with inactive disease at two or more yearly visits developed less cumulative joint damage than did those in such a state at only one visit [32]. These data suggest that it is important not only to reach remission, but also to maintain this state. It will be important to determine whether RA patients in sustained remission have less disease destruction compared with those not in sustained remission.

In a recently published study, we showed that an increased number of visits in remission was associated with reduced radiographic damage [30]. The goal of the current study was to describe the duration of remission with different criteria; we did not examine how patients achieved remission in this study. This will be the focus of future work.

The BRASS cohort represents patients from one academic practice setting, and data are gathered over a long period. In this single-center cohort, most RA patients entered the cohort with longstanding disease. Because disease activity was measured yearly in BRASS, it is possible that a patient's disease flared between visits. Thus, this limitation of our data would strengthen the conclusion that one time point of remission in no guarantee for sustained remission. Also this will not affect the comparisons of different remission criteria in the survival analysis, because all remission criteria were measured at similar time points.

\section{Conclusion}

Recently published recommendations for the management of RA by EULAR suggest that as long as a target of remission or low disease activity has not been reached, treatment should be adjusted by frequent and strict monitoring [2]. Although remission without respect to duration is a good goal, it is not the most important target for therapy. Data from our study confirm that even after reaching remission, strict monitoring is required, as fewer than half of the patients in clinical practice will not sustain remission for more than 1 year.

\footnotetext{
Abbreviations

ACR: American College of Rheumatology; BRASS: Brigham Rheumatoid Arthritis Sequential Study; CDAl: Clinical Disease Activity Index; CRP: Creactive protein; DAS: Disease Activity Score; ESR: erythrocyte sedimentation rate; EULAR: European League Against Rheumatism; IQR: interquartile range; OMERACT: Outcome Measures in Rheumatology Initiative; RA: rheumatoid arthritis; SDAl: Simplified Disease Activity Index.
}

\section{Acknowledgements}

Dr Femke Prince is supported by the Niels Stensen Foundation, The Netherlands, and Dr Daniel Solomon is supported by the National Institutes of Health [K24AR055989 and RC2AR058989]. BRASS is funded by Crescendo Bioscience and Biogen Idec. None of these funders had a role in the design, collection, analysis, or interpretation of data, in the writing of the manuscript, or in the decision to submit the manuscript for publication.

\section{Authors' contributions}

FP contributed to the design of the study, conducted the initial statistical analyses, contributed to the interpretation of data, and wrote the first draft of the manuscript. VP, NS, Cl, and MW contributed to the design of the study and interpretation of data. BL, JC, and MF contributed to the management and analysis of data. DS contributed to the design of the study, analysis and interpretation of data, and helped to write the first draft of the manuscript. All authors critically reviewed, contributed to, and approved the final manuscript.

\section{Competing interests}

Dr Femke Prince has received financial support for educational purposes from Abbott, Bristol-Myers Squib, Novartis Pharma, Teva Pharma, and Wyeth Pharmaceuticals, and a consulting fee from Bristol-Myers Squib. Dr Nancy Shadick has received research grant support from Amgen, Crescendo Bioscience, Biogen Idec, Genentech, Abbott, and Medimmune. Prof. Michael Weinblatt has received grant support from Biogen Idec, Crescendo Bioscience, and consultant fees from Biogen Idec and Crescendo Bioscience. Dr Daniel Solomon has received financial support for educational purposes from Bristol-Myers Squibb and research grants from Abbott Immunology and Amgen.

Received: 11 July 2011 Revised: 29 January 2012

Accepted: 19 March 2012 Published: 19 March 2012

\section{References}

1. Sokka T: Long-term outcomes of rheumatoid arthritis. Current Opin Rheumatol 2009, 21:284-290.

2. Smolen JS, Landewe R, Breedveld FC, Dougados M, Emery P, GaujouxViala C, Gorter S, Knevel R, Nam J, Schoels M, Aletaha D, Buch M, Gossec L, Huizinga T, Bijlsma JW, Burmester G, Combe B, Cutolo M, Gabay C, GomezReino J, Kouloumas M, Kvien TK, Martin-Mola E, Mclnnes I, Pavelka K, van Riel P, Scholte M, Scott DL, Sokka T, Valesini G, et al: EULAR recommendations for the management of rheumatoid arthritis with synthetic and biological disease-modifying antirheumatic drugs. Ann Rheum Dis 2010, 69:964-975.

3. Bykerk VP: Rheumatoid arthritis: 2011 remission criteria are a new benchmark for RA therapy. Nat Rev Rheumatol 2011, 7:317-318.

4. Aletaha D, Nell VP, Stamm T, Uffmann M, Pflugbeil S, Machold K, Smolen JS: Acute phase reactants add little to composite disease activity indices for rheumatoid arthritis: validation of a clinical activity score. Arthritis Res Ther 2005, 7:R796-806.

5. Pinals RS, Masi AT, Larsen RA: Preliminary criteria for clinical remission in rheumatoid arthritis. Arthritis Rheum 1981, 24:1308-1315.

6. Prevoo ML, van 't Hof MA, Kuper HH, van Leeuwen MA, van de Putte LB, van Riel PL: Modified disease activity scores that include twenty-eightjoint counts: development and validation in a prospective longitudinal study of patients with rheumatoid arthritis. Arthritis Rheum 1995, 38:44-48.

7. Smolen JS, Breedveld FC, Schiff MH, Kalden JR, Emery P, Eberl G, van Riel PL, Tugwell P: A simplified disease activity index for rheumatoid arthritis for use in clinical practice. Rheumatology (Oxford) 2003, 42:244-257.

8. Felson DT, Smolen J, Wells G, Zhang B, Van Tuyl LH, Funovits J, Aletaha D, Allaart CF: Predictive validity of the new preliminary ACR/EULAR definitions for remission in rheumatoid arthritis. Arthritis Rheum 2010, 62(Suppl 10):2108.

9. Felson DT, Smolen JS, Wells G, Zhang B, Van Tuyl LH, Funovits J, Aletaha D, Allaart CF, Bathon J, Bombardier S: American College of Rheumatology/ European League Against Rheumatism Provisional Definition of Remission in Rheumatoid Arthritis for Clinical Trials. Arthritis Rheum 2011, 63:573-586.

10. O'Dell JR, Mikuls TR: To improve outcomes we must define and measure them: toward defining remission in rheumatoid arthritis. Arthritis Rheum 2011, 63:587-589.

11. Jacobsson LT, Hetland ML: New remission criteria for RA: "modern times" in rheumatology: not a silent film, rather a 3D movie. Ann Rheum Dis 2011, 70:401-403. 
12. Schoels M, Knevel R, Aletaha D, Bijlsma JW, Breedveld FC, Boumpas DT, Burmester G, Combe B, Cutolo M, Dougados M, Emery P, van der Heijde D, Huizinga TW, Kalden J, Keystone EC, Kvien TK, Martin-Mola E, Montecucco C, de Wit M, Smolen JS: Evidence for treating rheumatoid arthritis to target: results of a systematic literature search. Ann Rheum Dis 2010, 69:638-643.

13. Smolen JS, Aletaha D, Bijlsma JW, Breedveld FC, Boumpas D, Burmester G, Combe B, Cutolo M, de Wit M, Dougados M, Emery P, Gibofsky A, GomezReino JJ, Haraoui B, Kalden J, Keystone EC, Kvien TK, McInnes I, MartinMola E, Montecucco C, Schoels M, van der Heijde D, T2T Expert Committee: Treating rheumatoid arthritis to target: recommendations of an international task force. Ann Rheum Dis 2010, 69:631-637.

14. lannaccone CK, Lee YC, Cui J, Frits ML, Glass RJ, Plenge RM, Solomon DH, Weinblatt ME, Shadick NA: Using genetic and clinical data to understand response to disease-modifying anti-rheumatic drug therapy: data from the Brigham and Women's Hospital Rheumatoid Arthritis Sequential Study. Rheumatology (Oxford) 2011, 50:40-46.

15. Inoue E, Yamanaka H, Hara M, Tomatsu T, Kamatani N: Comparison of Disease Activity Score (DAS)28- erythrocyte sedimentation rate and DAS28- C-reactive protein threshold values. Ann Rheum Dis 2007, 66:407-409.

16. Castrejon I, Ortiz AM, Toledano E, Castaneda S, Garcia-Vadillo A, Patino E, Gonzalez-Alvaro I: Estimated cutoff points for the 28-joint disease activity score based on C-reactive protein in a longitudinal register of early arthritis. J Rheumatol 2010, 37:1439-1443.

17. Verschueren P, Esselens G, Westhovens R: Predictors of remission, normalized physical function, and changes in the working situation during follow-up of patients with early rheumatoid arthritis: an observational study. Scand J Rheumatol 2009, 38:166-172.

18. Balsa A, Del Amo J, Blanco F, Caliz R, Silva L, Sanmarti R, Martinez FG, Tejedor D, Artieda M, Pascual-Salcedo D, Oreiro N, Collado MD, Andreu JL, Graell E, Simón L, Martínez A, Mulero J: Prediction of functional impairment and remission in rheumatoid arthritis patients by biochemical variables and genetic polymorphisms. Rheumatology (Oxford) 2010, 49:458-466.

19. Schipper LG, Fransen J, den Broeder AA, Van Riel PL: Time to achieve remission determines time to be in remission. Arthritis Res Ther 2010, 12 R97.

20. Miriovsky BJ, Michaud K, Thiele GM, O'Dell JR, Cannon GW, Kerr G, Richards JS, Johnson D, Caplan L, Reimold A, Hooker R, Mikuls TR: Anti-CCP antibody and rheumatoid factor concentrations predict greater disease activity in men with rheumatoid arthritis. Ann Rheum Dis 2010, 69:1292-1297.

21. Raghunathan TE, Lepkowski JM, Van Hoewyk J, Solenberger PA: A multivariate technique for multiply imputing missing values using a sequence of regression models. Surv Methodol 2001, 27:85-95.

22. Mierau M, Schoels M, Gonda G, Fuchs J, Aletaha D, Smolen JS: Assessing remission in clinical practice. Rheumatology (Oxford) 2007, 46:975-979.

23. Sokka T, Hetland ML, Makinen H, Kautiainen $H$, Horslev-Petersen $K$, Luukkainen RK, Combe B, Badsha H, Drosos AA, Devlin J, Ferraccioli G, Morelli A, Hoekstra M, Majdan M, Sadkiewicz S, Belmonte M, Holmqvist AC, Choy E, Burmester GR, Tunc R, Dimić A, Nedović J, Stanković A, Bergman M, Toloza S, Pincus T, Questionnaires in Standard Monitoring of Patients With Rheumatoid Arthritis Group: Remission and rheumatoid arthritis: data on patients receiving usual care in twenty-four countries. Arthritis Rheum 2008, 58:2642-2651.

24. Sokka T, Makinen H, Hannonen P, Pincus T: Most people over age 50 in the general population do not meet ACR remission criteria or OMERACT minimal disease activity criteria for rheumatoid arthritis. Rheumatology (Oxford) 2007, 46:1020-1023.

25. Verstappen SM, van Albada-Kuipers GA, Bijlsma JW, Blaauw AA, Schenk Y, Haanen $\mathrm{HC}$, Jacobs JW: A good response to early DMARD treatment of patients with rheumatoid arthritis in the first year predicts remission during follow up. Ann Rheum Dis 2005, 64:38-43.

26. van der Heijde D, Klareskog L, Boers M, Landewe R, Codreanu C, Bolosiu HD, Pedersen R, Fatenejad S: Comparison of different definitions to classify remission and sustained remission: 1 year TEMPO results. Ann Rheum Dis 2005, 64:1582-1587.

27. Shahouri SH, Michaud K, Mikuls TR, Caplan L, Shaver TS, Anderson JD, Weidensaul DN, Busch RE, Wang S, Wolfe F: Remission of rheumatoid arthritis in clinical practice: application of the ACR/EULAR 2011 remission criteria. Arthritis Rheum 2011, 63:3204-3215.

28. Molenaar ET, Voskuyl AE, Dinant HJ, Bezemer PD, Boers M, Dijkmans BA: Progression of radiologic damage in patients with rheumatoid arthritis in clinical remission. Arthritis Rheum 2004, 50:36-42.

29. Molenaar ET, Lems WF, Dijkmans BA, de Koning MH, van de Stadt RJ, Voskuyl AE: Levels of markers of bone resorption are moderately increased in patients with inactive rheumatoid arthritis. Rheumatology (Oxford) 2000, 39:742-744.

30. Lillegraven S, Prince FH, Shadick NA, Bykerk VP, Lu B, Frits ML, lannaccone CK, Kvien TK, Haavardsholm EA, Weinblatt ME, Solomon DH: Remission and radiographic outcome in rheumatoid arthritis: application of the 2011 ACR/EULAR remission criteria in an observational cohort. Ann Rheum Dis 2011.

31. Isaacs JD: The changing face of rheumatoid arthritis: sustained remission for all? Nat Rev Immunol 2010, 10:605-611.

32. Magnani A, Pistorio A, Magni-Manzoni S, Falcone A, Lombardini G, Bandeira M, Rossi F, Sala I, Martini A, Ravelli A: Achievement of a state of inactive disease at least once in the first 5 years predicts better outcome of patients with polyarticular juvenile idiopathic arthritis. J Rheumatol 2009, 36:628-634.

doi:10.1186/ar3785

Cite this article as: Prince et al: Sustained rheumatoid arthritis remission is uncommon in clinical practice. Arthritis Research \& Therapy 2012 14:R68.

\section{Submit your next manuscript to BioMed Central and take full advantage of:}

- Convenient online submission

- Thorough peer review

- No space constraints or color figure charges

- Immediate publication on acceptance

- Inclusion in PubMed, CAS, Scopus and Google Scholar

- Research which is freely available for redistribution

Submit your manuscript at www.biomedcentral.com/submit
Biomed Central 